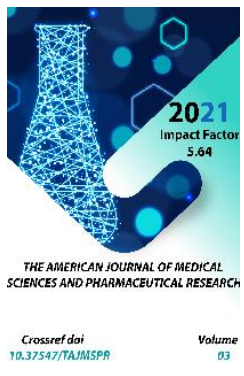

Copyright: Original content from this work may be used under the terms of the creative commons attributes 4.0 licence.

\section{Hygienic Assessment Of Emission Influence From A Chemical Plant On Population's Household Conditions, Well- Being And Health}

\author{
Zainab Naimova \\ Senior Lecturer, Samarkand State Medical Institute, Uzbekistan \\ Khurliman Kurbanova \\ Assistant, Samarkand State Medical Institute, Uzbekistan \\ Honbuvi Khakimova \\ Senior Lecturer, Samarkand State Medical Institute, Uzbekistan \\ Zokir Bulyaev \\ Assistant, Samarkand State Medical Institute, Samarkand, Uzbekistan
}

\title{
ABSTRACT
}

The impact of economic activity, as well as scientific and technological progress on the environment is characterized by production of large amount of pollutants, waste and other factors that lead to changes in natural landscapes, pollution of the atmosphere and natural water resources. Continuous increase and expansion in industrial production of chemicals inevitably entail rise of their environmental load. Exceeding thresholds ecosystems' reliability under the influence of extreme anthropogenic factors can cause significant changes in conditions of existence and functioning of biogeocenoses.

\section{KEYWORDS}

Ecological system, ammophos production, ecotoxicants, pollution, social living conditions, respiratory diseases.

\section{INTRODUCTION}

Development of new branches of chemical industry, increase in their capacity and growth

rates have changed qualitative and quantitative composition of industrial 
emissions. Production of land, air and water transport increased. These processes have acquired such proportions in recent years that a new scientific direction has emerged ecotoxicology that deals with study harmful effects of chemicals and protection of living organisms that make up ecosystems, including humans, from them. Moreover, there was a significant increase in the volume of mineral fertilizers production, the most important and valuable of which is ammophos - a complex nitrogen-phosphorus chemical compound with more than 47 million tons per year output. Production and widespread use of this type of mineral fertilizers in agriculture highly contributes to air pollution also. Study of ammophos dust, fluoride-sulfuric gases, ammonia and sulfuric acid vapors in contaminated zones showed that these substances are found in the air at a distance of more than $10 \mathrm{~km}$ from the plant. Chemical agents - ecotoxicants found in industrial emissions in an open atmosphere, even in low concentrations, have toxicity and allergenicity characteristics causing nonspecific changes in a living organism and increase of organism's general reactivity. Ecotoxicants interact with living organisms when spreading and transforming in ecological systems (water, soil, atmospheric air). Methodological issues of studying the health of child and adolescent population have not yet been sufficiently developed due to the impact of adverse environmental factors. Assessing danger rate of real air pollution on the health of children exposed to emissions from of ammophos fertilizers production is also poorly studied. In this regard, there is a possibility of negative effect of ammophos dust on the living conditions and well-being of the population, health of children and adolescents due to its constant intake into the body through such objects of external environment as air, water and food. Therefore, it is necessary to carry out an in-depth study of the effect of atmospheric pollution on living conditions and well-being of the population, health, genetic, and reproductive functions of a person.

\section{OBJECTIVE}

To study the effect of emissions from ammophos production on living conditions and well-being of population, health of children and adolescents, as well as to develop a set of health-improving and preventive measures in the zone of influence of a chemical plant. It has been proved that indicators of physical development, morbidity, prevalence of chronic pathology, the state of cardiorespiratory system and immune status of the body of children and adolescents is a criterion for assessing the impact of atmospheric pollution of ammophos production on the health of children and adolescents.

\section{MATERIAL AND RESEARCH METHODS}

In order to study the impact, a special questionnaire was developed with questions that made it possible to express subjective opinion of the impact of emissions from Samarkand Chemical Plant (SCZ) on living conditions, general well-being and health of the population that occasionally depends on the distance from source of pollution. During hygienic assessment of impact of ammophos production emissions, it was necessary to choose a control area. In this regard, Siab district, located more than $30 \mathrm{~km}$ from the chemical plant, was chosen. Emission criteria were:

Absence of specific pollutants typical for the SCZ (ammophos dust, sulfuric acid vapor, 
fluoric and sulfurous gases, etc.) in the atmospheric air of the area;

Spread of emissions is carried out along wind rose - to the West, i.e. in the direction from Siab region but excluding it.

Social living conditions for industrial and control regions of Samarkand were identical (established in the course of sociological research). Survey of the population living in the area affected by emissions was carried out twice. Static processing of questionnaire results identified 4 zones with different chemical load. In the first zone (from 2,000 to 3,000 meters from the source of pollution), all respondents considered the air to be polluted, and more than half of them gave positive answers to all the questions posed. In the second and third zones (from 3000 to 6000 meters) the same trend was observed, but with a slight decrease in affirmative answers to the questionnaire. And only in the fourth zone (6000-8000m) from the source of pollution, only $55,3 \%$ of the respondents believed that the atmospheric air was polluted. Attention is drawn to the data of population's answers on the impact of plant emissions on health (complaints of headache, dizziness, sleep disturbance, reflex cough, etc.). The presented materials show that $84.8 \%$ of all the respondents living within two or three kilometers from the plant expressed similar complaints, subjectively linking them to air pollution. As the distance from the area affected by the plant's emissions decreased, the number of complaints about poor health decreased too.

If the analysis of the questionnaire responses gave a subjective characterization of air pollution level, then observations of vegetation and farm animals in these zones showed that the farther from the source of pollution one or another organism is, the less is the level of chemical emissions impact. Thus, in vegetation in the immediate vicinity of the source of pollution (especially up to $3 \mathrm{~km}$ from the plant), leaves turned yellow and curled prematurely, yield of fruit trees decreased and in some cases they even died. Characteristic dark brown spots appeared on the leaves of stone fruits after which they dried out and fell off. Young animals (sheep, goats) lost their teeth. Young growth gained weight poorly and often died. This appears to be related to exposure to high levels of fluorinated substances in air, water and feed. This assumption is also confirmed by mass death of bees and silkworm caterpillars observed in the area affected by emissions.

\section{CONCLUSIONS}

Based on the studies carried out, it can be concluded that the compared areas were of the same type. This made it possible to compare physical development and level of general morbidity of the population. At the same time, such estimates of subjective indicators as the sense of smell, irritant effect on the upper respiratory tract and mucous membranes of the eyes, headache, feeling unwell, malaise, etc. were taken into account, which made it possible to indirectly estimate the area of atmospheric air pollution by emissions from a chemical plant. The impact of anthropogenic air pollution leads to the decrease of health level especially during the period of increased sensitivity of the body to the effects of chemical factors, i.e. children and adolescents. Influence of atmospheric air pollution from chemical production on the health of children has a regional specificity, not 
only due to various natural climatic and social characteristics, but also with a variety of chemicals. Quantitative links in such subsystems urgently require study from regional point of view. Timely identification of deviations in children's health will make it possible to carry out necessary sanitaryhygienic and preventive health measures, avoiding chronicity of pathological process.

It should be noted that the above phenomenon is undoubtedly related to the influence of chemical plant emissions. At the beginning of the study, there were a total of 86.8\% ( $m<0.05)$ complaints on smell that decreased to only $39.7 \%$. after introduction of health-improving measures. Accordingly, the number of complaints about poor health, living conditions (difficulty in ventilating apartments and drying clothes), as well as deterioration of vegetation, also decreased. Consequently, health improvement measures carried out for sanitary protection of the atmospheric air in the area of SCZ allowed to reduce atmospheric air pollution with the use of studied substances and this led to almost $5 \%$ reduction of complaints from the population about poor living conditions and well-being.

Thus, observations unambiguously show that the existing 1000-meter sanitary protection zone does not provide normal housing and living conditions for the population living in the impact zone of SCZ and creates a real danger to the health of children and adolescents. Consequently, the results obtained confirm the need to identify high-risk-group children living in most contaminated areas from the very first years of life in order to carry out a wide range of health-improving measures and proper organization of medical examination. They are the children who should be covered by comprehensive medical and recreational activities. Timely identification of deviations in children's health will make it possible to carry out sanitary-hygienic, preventive and healthimproving measures in time and to prevent chronicity of pathological process.

\section{REFERENCES}

1. Shandala M.G., Zvinyatskovsky Ya.I. Determination of the role of individual factors in the complex influence of the environment on public health. /Hygiene and sanitation. 1981. No.9. P.4-9.

2. Shandala MG, Zvinyatskovskaya Ya.I. Methodological approaches to the study of complex influence of the environment on public health. / Hygiene and sanitation. 1975. No.11. P.5-10.

3. Bolotniy A.V., Pismennaya M.V., Akoronko S.L. Transformation of organophosphorus pesticides antio and chlorophos in the environment // Hygiene and sanitation. 1978. No.5. P.28-31.

4. Agrochemicals in the environment / E.Hainisch, H.Paukke, D.Nagel, D.Hansen / Moscow: Kolos, 1979. 358 p.

5. Izrael Yu.A. Ecology and control of natural environment. Moscow: Gidrometeoizdat, 1984. $560 \mathrm{p}$.

6. Antonovich E.A., Gumenniy V.S. Improving approaches to assessing the harm and danger of pesticides and development of hygienic regulations // Hygiene and Sanitation. 1981. No.1. p.15-18.

7. Vengorek V. Pesticide circulation in the agrocenosis // Agrochemistry. 1983. №1. p.93-101.

8. L.V. Golubev. Usage of agrochemicals and environment // Plant protection. Saratov, 1993. P.4-11. 
The American Journal of Medical Sciences and Pharmaceutical Research

(ISSN - 2689-1026)

Published: January 22, 2021| Pages: 76-80

IMPACT FACTOR

2021: 5.64

Doi: https://doi.org/10.37547/TAJMSPR/Volume03Issue01-11

OCLC - 1121105510

9. Zakharenko V.A., Melnikov N.N. Pesticides in the modern world // Agrochemistry. 1996. No.1. p.100-108.

10. I.Otajonov, G.Shaykhova, F.Salomova, Kh.Kurbanova, M.Nazarova, Kh.Kurbonov. Effectiveness of diet in experimental chronic kidney disease. European Journal of Molecular \& Clinical Medicine , 2020 , Volume 7, Issue 2, Pages 1097-1109 